\title{
Electrospun nanofibers from cyclodextrin inclusion complexes with cineole and p-cymene: enhanced water solubility and thermal stability
}

\author{
Asli Celebioglu, Zehra Irem Yildiz \& Tamer Uyar* (D) \\ Institute of Materials Science \& Nanotechnology, UNAM-National Nanotechnology Research Center, Bilkent University, Ankara 06800, \\ Turkey
}

(Received 8 March 2017; Accepted in revised form 9 July 2017)

Summary The electrospinning of self-standing nanofibrous webs from inclusion complexes (IC) of cineole and $p$-cymene with two modified cyclodextrins (HP $\beta C D, H P \gamma C D)$ was achieved without using carrier polymeric matrix. Although they are highly volatile, certain amount of cineole and $p$-cymene was protected in cyclodextrin inclusion complexes nanofibers (CD-IC-NF). That is, $68.4 \%, 78.1 \%, 54.5 \%$ and $44.0 \%(\mathrm{w} /$ w) of active agent were preserved in cineole/HP $\beta C D-I C-N F$, cineole/HP $\gamma$ CD-IC-NF, $p$-cymene/HP $\beta C D$ IC-NF and $p$-cymene/HP $\gamma \mathrm{CD}$-IC-NF, respectively. Remarkable, high thermal stability for cineole $\left(\sim 150{ }^{\circ} \mathrm{C}-270{ }^{\circ} \mathrm{C}\right)$ and $p$-cymene $\left(\sim 150^{\circ} \mathrm{C}-275^{\circ} \mathrm{C}\right)$ was achieved for CD-IC-NF samples due to CD-IC formation. The water solubility of cineole and $p$-cymene was significantly improved by inclusion complexation where CD-IC-NF samples become readily dissolved in water. In brief, essential oils and flavours such as cineole and $p$-cymene could be applicable in food and oral care applications owing to their fastdissolving behaviour along with high water solubility, enhanced thermal stability and free-standing feature of CD-IC-NF webs.

Keywords Cineole, cyclodextrin, electrospinning, essential oils, $p$-cymene, nanofiber, thermal stability, water solubility.

\section{Introduction}

Essential oils, also known as volatile oils, are composed of highly concentrated hydrophobic volatile aroma compounds. Due to their distinctive properties such as antibacterial, antioxidant, antifungal, antiseptic and fragrance, essential oils are widely used in medical, food and cosmetic industry (Bakkali et al., 2008). However, essential oils have major problems due to their highly volatile nature and low water solubility; therefore, encapsulation is often applied to improve the efficiency and long-term shelf life of essential oils (Marques, 2010; Navarro et al., 2011). Cyclodextrins (CD), cyclic oligosaccharides having truncated-shape molecular structure, are capable of forming noncovalent host-guest inclusion complexes (IC) with variety of molecules including flavours, fragrances and essential oils (Del Valle, 2004; Szejtli, 1998). Due to their hydrophobic cavity, $\mathrm{CDs}$ are quite applicable for molecular encapsulation of flavours/fragrances/

*Correspondent: Email: tamer@unam.bilkent.edu.tr essential oils for food/cosmetic/textile applications. The cyclodextrin inclusion complexation (CD-IC) with flavours/fragrances/essential oils provides higher stability and shelf life for these volatile and hydrophobic active agents by protecting them against evaporation, degradation and oxidation. Moreover, CD-IC facilitates high water solubility for such active agents and additionally offers control release of flavours/fragrances/essential oils (Marques, 2010; Navarro et al., 2011).

Electrospinning is becoming one of the promising encapsulation methods in which variety of the active agents such as drugs (Hu et al., 2014) and food additives (Noruzi, 2016) are encapsulated in the electrospun nanofibrous matrix. In general, electrospinning is a room temperature process in which active agents (food additives, drugs, etc.) can be easily incorporated into polymeric nanofiber matrix (Mittal et al., 2012; Wendorff et al., 2012). Yet, in our recent studies, we have shown that the encapsulation efficiency of volatile additives in electrospun polymeric nanofiber matrix such as menthol (Uyar et al., 2009a,b, 2011), vanillin (Kayaci \& Uyar, 2012), eugenol (Kayaci et al., 2013), 
geraniol (Kayaci et al., 2014) and allyl isothiocyanate (Aytac et al., 2014) was very poor without the use of CD-IC. The high amount of such volatile additives could only be preserved in the electrospun polymeric nanofiber matrix by forming CD-IC. The other challenge was to increase the loading per cent of these active agents in the nanofiber matrix. When carrier polymeric matrix is used, the loading of the active agents in the electrospun nanofiber matrix is often limited between 3 and $5 \%(\mathrm{w} / \mathrm{w}$, with respect to fiber matrix) in the case CD-IC active agents were used. It is because the electrospinning of uniform nanofibers is not quite possible from polymeric solution incorporating higher amount of CD-IC (i.e. $50 \%(\mathrm{w} / \mathrm{w})$ CD-IC corresponds to $3 \%-5 \%$ active agent when $1: 1$ molar ratio of CD:active agent is used). Nevertheless, in our recent studies, we were able to obtain electrospun nanofiber matrix containing higher amount of active agents (loading of $\sim 10 \%-25 \%(\mathrm{w} / \mathrm{w})$ ) from pure CDIC systems without using any carrier polymer matrix for the electrospinning (Celebioglu \& Uyar, 2011, 2017; Celebioglu et al., 2014, 2016; Aytac et al., 2016a, b, 2017).

The essential oil constituents such cineole and $p$-cymene are commonly found in plants; cineole is found in eucalyptus oil, and $p$-cymene is a constituent of cumin and thyme oil. Cineole and $p$-cymene are commonly used in food industry as flavour/fragrance agent; however, they are quite volatile and they are poorly water soluble which sometimes limit their use (Astray et al., 2010; Serafini et al., 2011). In this study, inclusion complexes between guest molecules (cineole and $p$-cymene) and host molecule (CD) were prepared with 1:1 molar ratio. Highly concentrated cineole/CD-IC and $p$-cymene/CD-IC aqueous solutions (i.e. $160 \% \mathrm{CD}(\mathrm{w} / \mathrm{v})$ concentration in water) were used to perform the electrospinning of nanofibers from these CD-IC systems without using any polymeric carrier matrix. The size of $\mathrm{CD}$ cavity is very important for effective inclusion complexation, so two different $C D$ types (HP $\beta C D$ and $\mathrm{HP} \gamma \mathrm{CD}$ ) were used to find the most effective CD-IC for cineole and $p$-cymene. The nanofibers from CD-IC with cineole and $p$-cymene (cineole/HPßCD-IC-NF, cineole/HP $\gamma$ CD-IC-NF, $\quad p$-cymene/HP $\beta C D$-IC-NF and $p$-cymene/HP $\gamma \mathrm{CD}$-IC-NF) were produced by electrospinning. The self-standing and handy nanofibrous webs from these CD-IC systems were successfully obtained. The water solubility and thermal stability of $p$-cymene and cineole were studied for these CDIC nanofibrous webs. We observed that, in addition to thermal stability enhancement, the fast-dissolving character along with high water solubility of cineole and $p$-cymene was also achieved for these electrospun CD-IC nanofibers.

\section{Materials and methods}

\section{Materials}

p-Cymene (97\% purity, Alfa-Aesar) and 1,4-cineole (mixture of isomers, $\geq 85 \%$ (GC), 1,4-cineol, $\sim 75 \%$ and 1,8-cineol, $\sim 15 \%$, Aldrich) were obtained commercially. The modified cyclodextrins, hydroxypropyl- $\beta$ cyclodextrin (HP $\beta C D$ ) (degree of substitution: 0.6, Cavasol ${ }^{\circledR}$ W7 HP Pharma) and hydroxypropyl- $\gamma$-cyclodextrin $(\mathrm{HP} \gamma \mathrm{CD})$ (degree of substitution: 0.6, Cavasol ${ }^{\circledR} \mathrm{W} 8 \mathrm{HP}$ ) were kindly donated by Wacker Chemie AG (Germany). Potassium bromide (KBr, 99\%, FTIR grade, Sigma-Aldrich) and deuterated dimethylsulfoxide (d6-DMSO, deuteration degree min. $99.8 \%$ for NMR spectroscopy, Merck) were used in this study. The water used was from a Millipore Milli-Q ultrapure water system. The materials were used as received without any further purification process.

\section{Preparation of CD-IC solutions and electrospinning of CD-IC nanofibers}

The inclusion complexes (IC) of cineole and $p$-cymene with $\mathrm{HP} \beta \mathrm{CD}$ and $\mathrm{HP} \gamma \mathrm{CD}$ were prepared using 1:1 molar ratio of $\mathrm{CD}$ :guest in water. The $\mathrm{CD}$ concentrations for the electrospinning of HP $\beta C D$ and $\mathrm{HP} \gamma \mathrm{CD}$ in water were determined from our previous study to have bead-free and uniform nanofibers (Celebioglu \& Uyar, 2012). Firstly, HP $\beta C D(160 \%, w / v)$ and $\mathrm{HP} \gamma \mathrm{CD}(160 \%, \mathrm{w} / \mathrm{v})$ were dissolved in water separately, then cineole and $p$-cymene were added dropwise to these clear aqueous $\mathrm{CD}$ solutions and then stirred overnight.

Each cineole/CD-IC and $p$-cymene/CD-IC solution was placed in a plastic syringe $(1 \mathrm{~mL})$ fitted with a metallic needle (0.4-mm inner diameter). The electrospinning process was optimised as follow: the feed rate of solutions was between 0.5 and $1 \mathrm{~mL} / \mathrm{h}$ using a syringe pump (KD Scientific, KDS 101), the applied voltage was between 10 and $15 \mathrm{kV}$ (Matsusada, AU Series) and the tip-to-collector (stationary metal collector covered with a piece of aluminium foil) distance was $10-20 \mathrm{~cm}$. The electrospinning apparatus was enclosed in a Plexiglas box, and electrospinning was carried out in a horizontal set-up at $25{ }^{\circ} \mathrm{C}$ at $30 \%$ relative humidity.

\section{Measurements and characterization}

Solution viscosity and conductivity

A rheometer (Anton Paar, Physica CR 301) equipped with a cone/plate accessory (spindle type CP 20-4) was used to measure the viscosity of CD-IC solutions at a constant shear rate of $100 \mathrm{~s}^{-1}$ at $25^{\circ} \mathrm{C}$. The 
conductivity of the solutions was measured by a Multiparameter InoLab $^{\circledR}$ Multi 720 -WTW at room temperature.

\section{Scanning electron microscopy (SEM)}

The morphology of the electrospun nanofibers was investigated by SEM (FEI-Quanta 200 FEG). Samples were sputtered with $5 \mathrm{~nm} \mathrm{Au} / \mathrm{Pd}$ prior to SEM imaging. The average fiber diameter (AFD) was determined from the SEM images recorded from different location of samples by taking into account of around 100 fibers.

Fourier transform infrared spectroscopy (FTIR)

The infrared spectra of the samples were obtained using a FTIR spectrometer (Bruker-VERTEX70). The samples were mixed with $\mathrm{KBr}$ and pressed as pellets. FTIR spectra were recorded by 64 scans between 4000 and $400 \mathrm{~cm}^{-1}$ at a resolution of $4 \mathrm{~cm}^{-1}$.

\section{Thermal gravimetric analyzer (TGA)}

TGA (TA Q500) was used to study the thermal properties of the samples. The TGA of the samples was carried out from 25 to $500{ }^{\circ} \mathrm{C}$ at a $20{ }^{\circ} \mathrm{C} / \mathrm{min}$ heating rate, and nitrogen was used as a purge gas.

Proton nuclear magnetic resonance spectroscopy $\left({ }^{1} H-N M R\right)$ The molar ratios of $\mathrm{CD}$ :cineole and $\mathrm{CD}$ :p-cymene were determined by ${ }^{1} \mathrm{H}-\mathrm{NMR}$ (Bruker D PX-400) system. The electrospun cineole/CD-IC-NF and p-cymene/CD-IC-NF samples were dissolved in $d 6$-DMSO at the $20 \mathrm{~g} / \mathrm{L}$ concentration. The spectra were recorded at $400 \mathrm{MHz}$ and at 16 total scans. Integration of the chemical shifts $(\delta)$ given in parts per million $(\mathrm{ppm})$ of the samples was calculated using Mestrenova software.

\section{Phase solubility study of CD-IC and water solubility of CD-IC-NF}

Phase solubility analyses were carried in aqueous medium according to Higuchi and Connors method (Higuchi \& Connors, 1965). $10 \mathrm{~mL}$ of aqueous CD solutions was prepared ranging from 0 to $30 \mathrm{~mm}$ concentrations for CD:cineole and CD:p-cymene systems. Afterwards, excess amount of cineole and $p$-cymene was added to each of these systems. The solutions were stirred for $48 \mathrm{~h}$ at RT to reach equilibrium. Then, all solutions were filtered through $0.45 \mu \mathrm{m}$ membrane filter to remove undissolved part of guest molecules. Cineole and p-cymene concentration with respect to increasing $\mathrm{CD}$ concentration was determined using UV-Vis spectroscopy (Varian, Carry 100) at $240 \mathrm{~nm}$ and $266 \mathrm{~nm}$ for cineole and $p$-cymene, respectively. The phase solubility diagrams are plotted as the molar concentration of guest molecule vs. molar concentration of $\mathrm{CD}$. The experiment was carried out in triplicate, and average of three measurements was taken. Moreover, the apparent stability constant (Ks) of CD-IC was calculated from the phase solubility diagram according to the following equation:

$$
\mathrm{K}_{\mathrm{S}}=\frac{\text { slope }}{\mathrm{S}_{0}(1-\text { slope })}
$$

where $\mathrm{S}_{0}$ is the intrinsic solubility of active agents. Cineole $(\sim 0.02 \mathrm{mg} / \mathrm{mL})$ and $p$-cymene $(\sim 0.02 \mathrm{mg} / \mathrm{mL})$ have quite limited solubility in water (Yalkowsky \& $\mathrm{He}, 2003)$. For water solubility test, we put a web of cineole/CD-IC-NF and $p$-cymene/CD-IC-NF (approx. $3 \mathrm{~cm} * 3 \mathrm{~cm}$ ) into petri-dishes and poured water to observe the immediate dissolution of the CD-IC-NF samples. Both the photographs and videos were recorded during the dissolution tests.

\section{Results and discussion}

\section{Morphology of CD-IC-NF}

Highly concentrated aqueous CD-IC solutions $(160 \%$ $\mathrm{CD}(\mathrm{w} / \mathrm{v}))$ were prepared using two guest molecules (cineole and $p$-cymene) with two different $\mathrm{CD}$ types (HP $\beta C D$ and $\mathrm{HP} \gamma \mathrm{CD}$ ). Then, electrospinning was performed to obtain CD-IC-NF samples (Fig. 1 and Fig. S1a). The bead-free nanofibers (except $p$-cymene/ HP $\gamma$ CD-IC-NF) were successfully electrospun and free-standing nanofibrous webs along with flexible character were obtained from these CD-IC systems with a very high production yield (above 90\%) (Fig. 2). The same concentration of HPßCD $(160 \%$, $\mathrm{w} / \mathrm{v})$ and $\mathrm{HP} \gamma \mathrm{CD}(160 \%$, w/v) was used for the electrospinning of the each system, and the average fiber diameter (AFD) values were calculated as $765 \pm$ $320 \mathrm{~nm}, 785 \pm 265 \mathrm{~nm}$ and $550 \pm 385 \mathrm{~nm}$ for cineole/HP $\beta C D-I C-N F$, cineole/HP $\gamma$ CD-IC-NF and $p$ cymene/HPBCD-IC-NF, respectively (Table $\mathrm{S} 1$ and Fig. S2). Although the AFD value for each CD-ICNF was not very different from other, the slight variation was possibly due to the differences in conductivity and viscosity of the CD-IC solutions (Table S1). Generally, electrospinning of solutions having high conductivity and low viscosity resulted in thinner fibers due to the more stretching of the electrospinning jet (Uyar \& Besenbacher, 2008). Here, we observed a similar behaviour for CD-IC-NF samples where $p$-cymene/HP $\beta C D$-IC-NF $(550 \pm 385 \mathrm{~nm})$ has lowest AFD value, and the cineole/HP $\gamma \mathrm{CD}-\mathrm{IC}-\mathrm{NF}$ $(785 \pm 265 \mathrm{~nm})$ has the highest AFD value (Table S1). Although $p$-cymene/HP $\beta C D$-IC and cineole/HP $\beta C D$-IC solutions have a very similar conductivity $(\sim 16 \mu \mathrm{S} / \mathrm{cm})$, this is because $p$-cymene/HP $\beta C D$ IC has lower viscosity $(0.30 \mathrm{~Pa} \bullet \mathrm{s})$ that enables more stretching and therefore thinner fibers were produced during the electrospinning. 


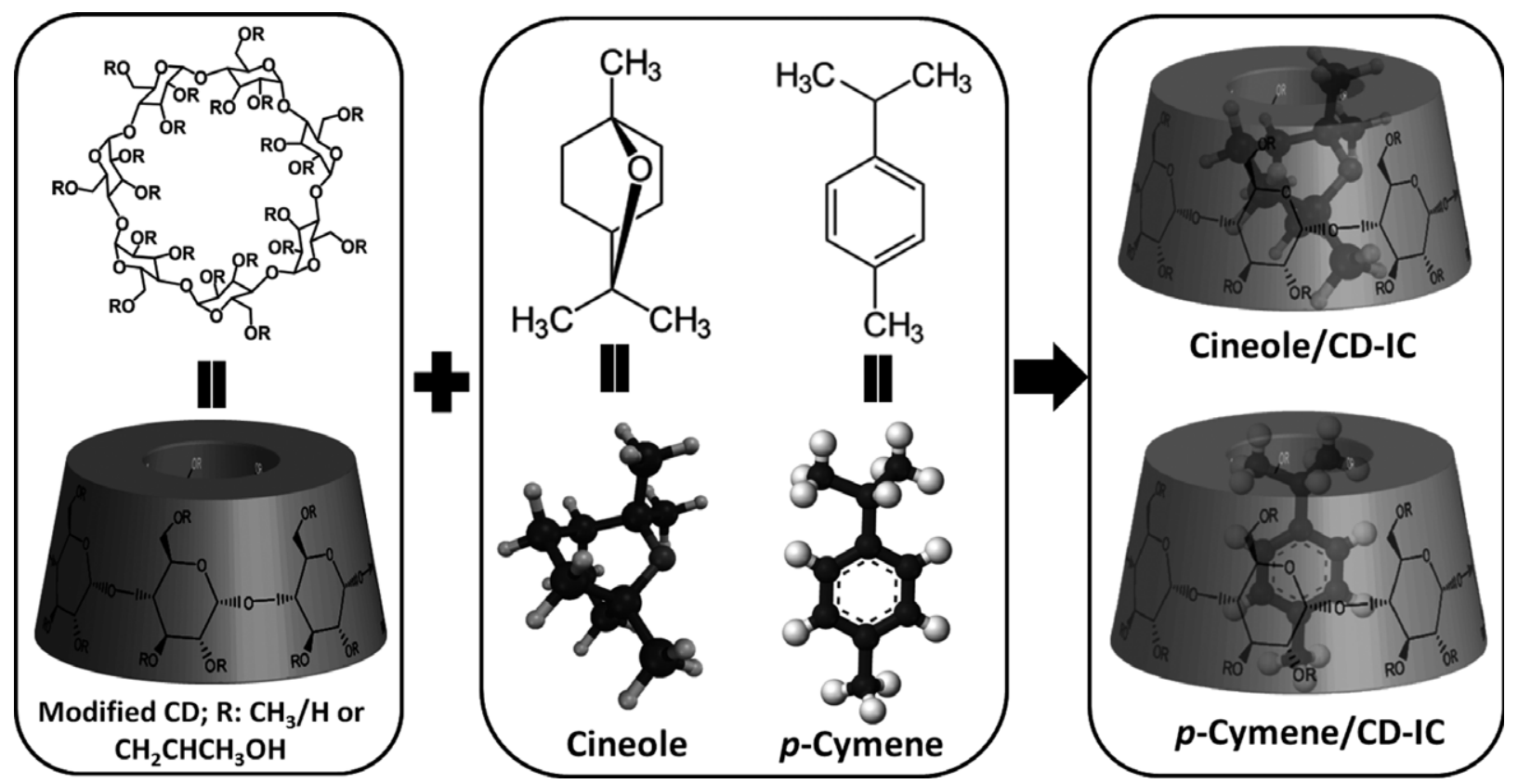

Figure 1 Chemical structure of modified $\mathrm{CD}$, cineole and $p$-cymene molecules, schematic representation of IC formation between $\mathrm{CD}$ and cineole or $p$-cymene.

Figure 2 Representative SEM images and the photographs (inset) of electrospun webs of (a) cineole/HP $\beta C D-I C-N F$, (b) cineole HP $\gamma$ CD-IC-NF, (c) $p$-cymene/HP $\beta C D-I C$ $\mathrm{NF}$ and (d) $p$-cymene $/ \mathrm{HP} \gamma \mathrm{CD}$-IC-NF. [Colour figure can be viewed at wileyonlinelibrary.com]
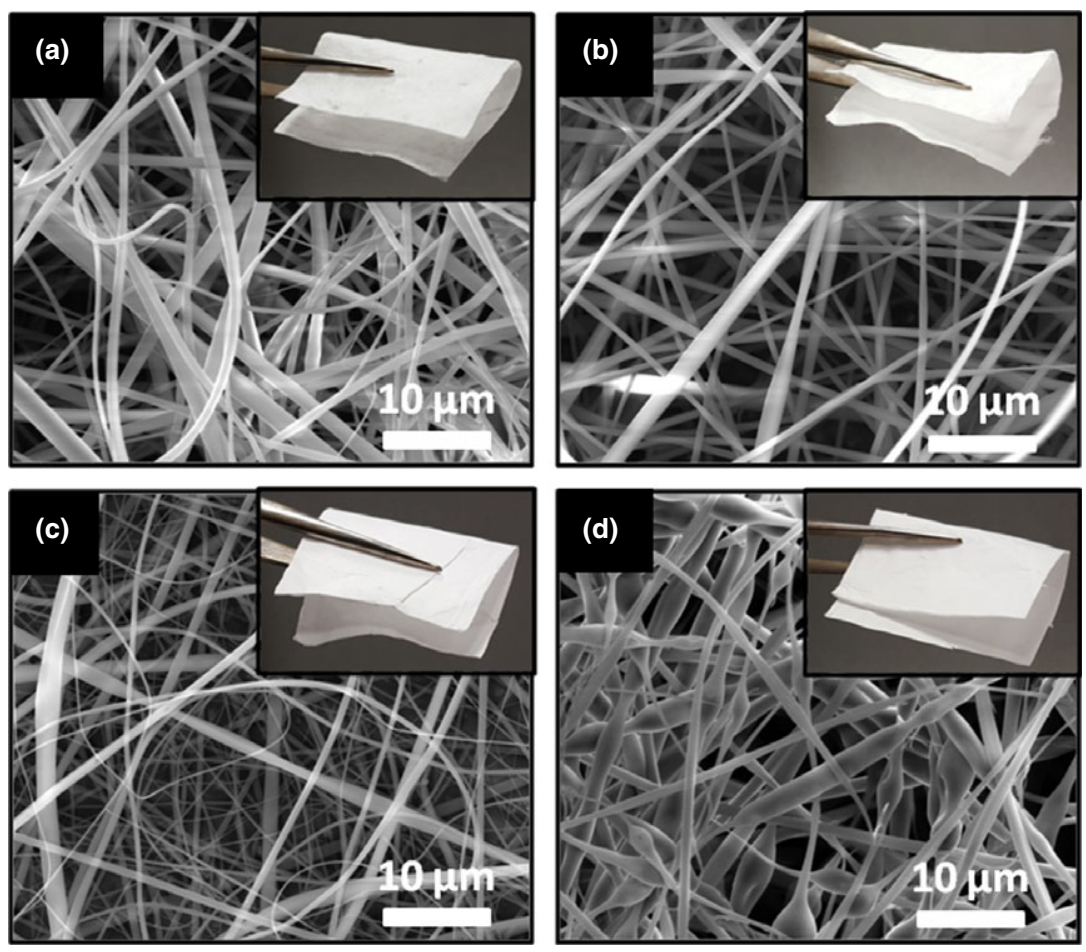

Structural Characterisation of CD-IC-NF

The FTIR analysis proved the presence of cineole and p-cymene in the CD-IC-NF samples (Fig. 3a,b and
Fig. S3). For all the CD-IC-NF samples, the salient absorption bands were observed at 1020, 1070 and $1150 \mathrm{~cm}^{-1}$ correspond to the coupled $\mathrm{C}-\mathrm{C} / \mathrm{C}-\mathrm{O}$ stretching vibrations and the antisymmetric stretching 
(a)

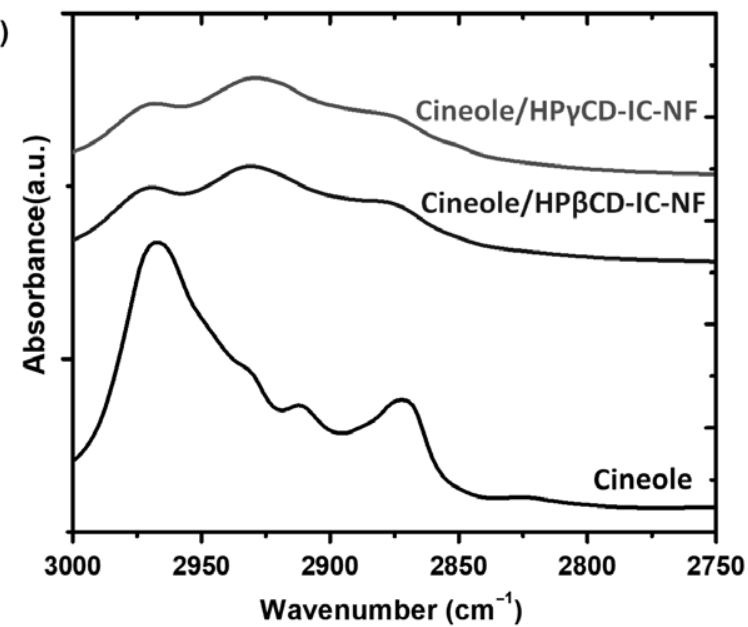

(c)

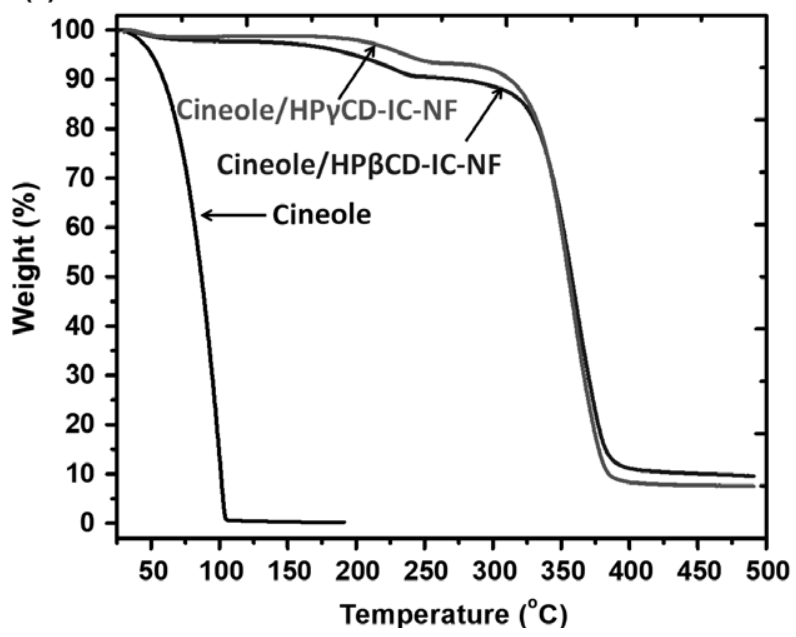

(b)

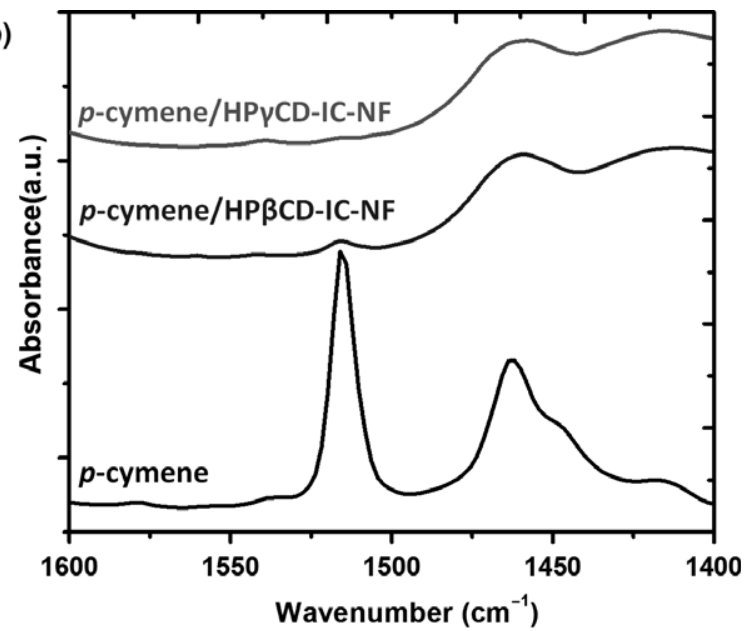

(d)

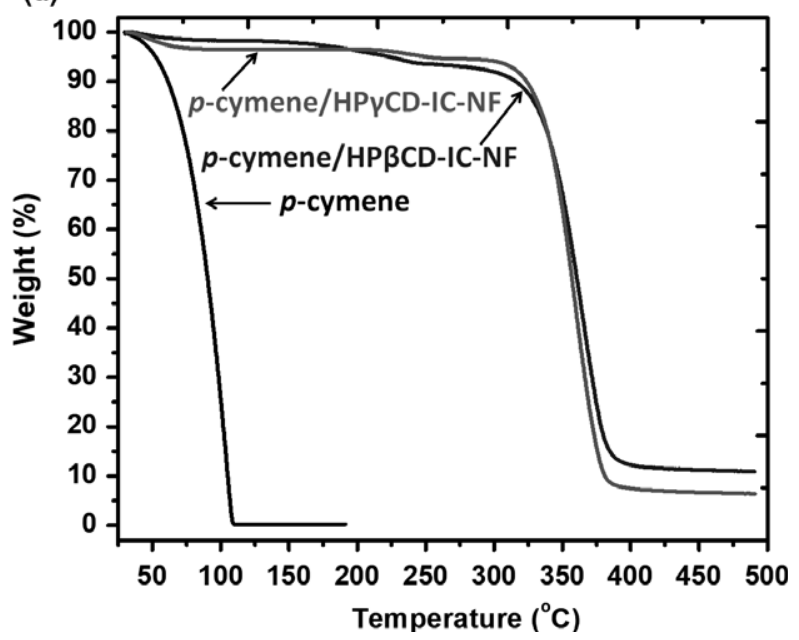

Figure 3 FTIR spectra of (a) cineole, cineole/HP $\beta$ CD-IC-NF, cineole/HP $\gamma$ CD-IC-NF and (b) $p$-cymene, $p$-cymene/HP $\beta C D-I C-N F, p$-cymene/ HP $\gamma$ CD-IC-NF. TGA thermograms of (c) cienole, cineole/HP $\beta$ CD-IC-NF, cineole/HP $\gamma$ CD-IC-NF and (d) $p$-cymene, $p$-cymene/HP $\beta C D-I C-$ $\mathrm{NF}, p$-cymene/HP $\gamma \mathrm{CD}-\mathrm{IC}-\mathrm{NF}$.

vibration of the $\mathrm{C}-\mathrm{O}-\mathrm{C}$ glycosidic bridge of $\mathrm{CD}$ molecules (Celebioglu et al., 2016). In case of cineole, there is characteristic peak range in $2872-2967 \mathrm{~cm}^{-1}$ corresponding to aromatic $\mathrm{C}-\mathrm{H}$ stretching which is also observed in cineole/HPBCD-IC-NF and cineole/ HP $\gamma$ CD-IC-NF (Narishetty \& Panchagnula, 2005) (Fig. 3a). In addition, FTIR spectrum of pure $p$-cymene exhibits the most significant characteristic peaks at $2870-2960 \mathrm{~cm}^{-1}$ and $1461-1515 \mathrm{~cm}^{-1}$ owing to aromatic C-H and C-C stretching, respectively (Serafini et al., 2011) (Fig. 3b). These absorption peaks are also observed in $p$-cymene/HP $\beta C D$-IC-NF and $p$-cymene/ $\mathrm{HP} \gamma \mathrm{CD}$-IC-NF confirming the existence of $p$-cymene in CD-IC-NF.

The initial molar ratio used for the preparation of CD-IC solutions was chosen as 1:1 between guest molecules (cineole and p-cymene) and host CD
(HP $\beta C D$ and $\mathrm{HP} \gamma \mathrm{CD}$ ). However, as cineole and $p$-cymene are highly volatile, it is possible that during the electrospinning process and after the electrospinning (during storage), the loss of some amount of these active agents is anticipated due to evaporation. Here, we examined the molar ratio in the CD-IC-NF by ${ }^{1} \mathrm{H}-\mathrm{NMR}$ by dissolving them in $d 6$-DMSO. The integration of peaks at $1.01 \mathrm{ppm}$ (HP $\beta C D$ and HP $\gamma$ CD), 0.89-0.91 ppm (cineole) and 1.19-1.17 ppm ( $p$-cymene) was used to calculate the molar ratio of components in the CD-IC-NF (Fig. S4). The molar ratios of $\mathrm{CD}$ :cineole were found as 1.00:0.62 and 1.00:0.72 for cineole/HPBCD-IC-NF and cineole/ $\mathrm{HP} \gamma \mathrm{CD}-\mathrm{IC}-\mathrm{NF}$, respectively. The molar ratios of $\mathrm{CD}$ : $p$-cymene were found as 1.00:0.50 and 1.00:0.40 for $p$-cymene/HP $\beta C D$-IC-NF and $p$-cymene/HP $\gamma$ CD-IC$\mathrm{NF}$, respectively (Table $\mathrm{S} 2$ ). In short, ${ }^{1} \mathrm{H}-\mathrm{NMR}$ results 
revealed that considerable amount of cineole and p-cymene was preserved in CD-IC-NF after the electrospinning process and storage of the samples. The encapsulation efficiency was found as $68.4 \%, 78.1 \%$, $54.5 \%$ and $44.0 \%$ for cineole/HP $\beta C D-I C-N F$, cineole/ HP $\gamma$ CD-IC-NF, $p$-cymene/HP $\beta C D$-IC-NF and $p$-cymene $/ \mathrm{HP} \gamma \mathrm{CD}-\mathrm{IC}-\mathrm{NF}$, respectively.

\section{Thermal Characterisation of CD-IC-NF}

The thermal stability of the pure cineole and $p$-cymene and CD-IC-NF was analysed by TGA (Fig. 3c,d and Fig. S5). The TGA thermograms clearly show that both cineole and $p$-cymene are highly volatile and completely evaporated below $100{ }^{\circ} \mathrm{C}$. In the case of CD-IC-NF, three stages of weight losses were observed; the initial weight loss below $100{ }^{\circ} \mathrm{C}$ is due to water loss, the second weight loss between $135^{\circ} \mathrm{C}$ and $275^{\circ} \mathrm{C}$ is due to evaporation of active agents and the major weight loss above $300{ }^{\circ} \mathrm{C}$ is the main degradation of CD. For cineole/HP $\beta \mathrm{CD}-\mathrm{IC}-\mathrm{NF}$ and cineole/ $\mathrm{HP} \gamma \mathrm{CD}$-IC-NF, the evaporation of cineole occurred in the range of $135{ }^{\circ} \mathrm{C}-250{ }^{\circ} \mathrm{C}$ and $160{ }^{\circ} \mathrm{C}-270{ }^{\circ} \mathrm{C}$, respectively. In the case of $p$-cymene/HP $\beta \mathrm{CD}$-IC-NF and $p$-cymene $/ \mathrm{HP} \gamma \mathrm{CD}-\mathrm{IC}-\mathrm{NF}$, the evaporation of $p$ cymene occurred in the range of $145{ }^{\circ} \mathrm{C}-255^{\circ} \mathrm{C}$ and $195{ }^{\circ} \mathrm{C}-275^{\circ} \mathrm{C}$, respectively. TGA data clearly show that the evaporation of active agents in CD-IC-NF has shifted to quite a high temperature confirming the inclusion complex formation (Fig. 3c,d). Here, we have achieved high thermal stability for cineole and $p$ cymene by incorporating them into CD-IC-NF, and the results were very similar with our previous studies where we have also achieved high thermal stability for different volatile compounds such as limonene, geraniol, linalool and vanillin in their CD-IC-NF (Aytac et al., 2016a,b, 2017; Celebioglu et al., 2016). Therefore, electrospinning of polymer-free CD-IC-NF is a quite efficient encapsulation approach to enhance the thermal stability of active volatile compounds. Additionally, while the water $\%$ content $(\mathrm{w} / \mathrm{w}$, with respect to the sample) observed up to $100{ }^{\circ} \mathrm{C}$ is $4.8 \%$ and $5.8 \%$ for pure $\mathrm{HP} \beta C D$ and $\mathrm{HP} \gamma \mathrm{CD}$ nanofibers, respectively (as it was recorded in our previous study (Celebioglu \& Uyar, 2012)), the water content was decreased to $2.1 \%, 0.9 \%, 1.3 \%$ and $3.4 \%$ for cineole/ HP $\beta C D$-IC-NF, cineole/HP $\gamma$ CD-IC-NF, $p$-cymene/ HP $\beta C D$-IC-NF and $p$-cymene/HP $\gamma$ CD-IC-NF, respectively. The decrease in water content is an indication of the replacement of water molecules by active agent molecules in the cyclodextrin cavity for inclusion complexes. From the TGA data, the amount of active agent in CD-IC-NF is also calculated and summarised in Table S2. The weight ratio of active agents in cineole/HP $\beta C D-I C-N F$, cineole/HP $\gamma$ CD-IC-NF, $p$-cymene/HP $\beta C D$-IC-NF and $p$-cymene/HP $\gamma$ CD-IC-NF was calculated as $7.20 \%(\mathrm{w} / \mathrm{w}), 5.50 \%(\mathrm{w} / \mathrm{w}), 4.50 \%$ $(\mathrm{w} / \mathrm{w})$ and $2.00 \%(\mathrm{w} / \mathrm{w})$, respectively. According to this data, the molar ratio of CD:active agents was calculated as 1.00:0.70, 1.00:0.60, 1.00:0.50 and 1.00:0.24 for cineole/HP $\beta C D-I C-N F$, cineole/HP $\gamma$ CD-IC-NF, $p$-cymene/HP $\beta \mathrm{CD}$-IC-NF and $p$-cymene $/ \mathrm{HP} \gamma \mathrm{CD}$-IC$\mathrm{NF}$, respectively. TGA data also proved that certain amount of active agents in CD-IC-NF samples was presented and protected against evaporation during electrospinning process and during storage time of the samples. The weight $\%$ of active agents calculated from TGA data was not exactly the same but very close to the ones calculated from ${ }^{1} \mathrm{H}-\mathrm{NMR}$ data. In brief, both techniques revealed the presence and preservation of the cineole and p-cymene in the CDIC-NF by inclusion complexation. In addition, TGA and ${ }^{1} \mathrm{H}-\mathrm{NMR}$ data indicated that cineole was preserved more efficiently compared to $p$-cymene in CD-IC NF systems. Essentially, the geometric accommodation of guest molecules into the $\mathrm{CD}$ cavity determines the complexation efficiency. Thus, cineole most probably complexes with $\mathrm{CD}$ cavity more efficiently due to a good size match with the $\mathrm{CD}$ cavity when compared to $p$-cymene (Astray et al., 2010). Therefore, higher amount of cineole was preserved in the CD-IC$\mathrm{NF}$ during electrospinning process. Moreover, while cineole/HP $\beta$ CD-IC-NF and cineole/HP $\gamma$ CD-IC-NF protect cineole with similar efficiency, $p$-cymene/ HP $\gamma$ CD-IC-NF significantly has lower complexation efficiency compared to $p$-cymene/HP $\beta C D-I C-N F$. This may be because of the size mismatch with the CD cavity where the molecular size of $p$-cymene might play a critical role which hinders the stable interaction with $\mathrm{HP} \gamma \mathrm{CD}$ having bigger cavity size compared to HP $\beta C D$.

\section{Water Solubility of CD-IC-NF}

Cineole and p-cymene are commonly used in food industry as flavour/fragrance agent; yet, their poor water solubility may sometimes limit their use. Here, phase solubility test was performed to indicate the apparent solubility improvement of cineole and $p$-cymene as a function of $C D$ concentration. From this study, we have obtained three subtypes of A-type phase solubility diagram for different CD-IC systems. As described by Higuchi and Connors method (Higuchi \& Connors, 1965), while $\mathrm{A}_{\mathrm{L}}$-type stands for linear increases in guest solubility as a function of CD concentration, $\mathrm{A}_{\mathrm{P}}$-type is for positively deviation of isotherms and $\mathrm{A}_{\mathrm{N}}$-type is for negatively deviation of isotherms (Marques, 2010). In our case, phase solubility diagrams which belong to cineole $/ \mathrm{HP} \gamma \mathrm{CD}-\mathrm{IC}-\mathrm{NF}$ and $p$-cymene $/ \mathrm{HP} \gamma \mathrm{CD}$-IC-NF exhibited $\mathrm{A}_{\mathrm{L}}$-type pattern suggesting linear increment in the solubility of active agents with the increasing $\mathrm{HP} \gamma \mathrm{CD}$ concentration 
(Fig. S6). Additionally, this linear trend displayed 1:1 complex formation tendency of cineole or $p$-cymene with $\mathrm{HP} \gamma \mathrm{CD}$. In contrast, cineole/HP $\beta \mathrm{CD}$-IC-NF has $\mathrm{A}_{\mathrm{P}}$-type, and $p$-cymene/HP $\beta \mathrm{CD}$-IC-NF has $\mathrm{A}_{\mathrm{N}}$-type profile. This means, while the higher concentration of $\mathrm{HP} \beta C D$ is more effective for the solubilisation of cineole molecules, the higher concentration of HP $\beta C D$ is less effective for the solubilisation of $p$-cymene molecules (Marques, 2010). Additionally, in the chosen CD concentration range $(0-30 \mathrm{~mm}), \mathrm{HP} \gamma \mathrm{CD}$ has provided less solubility enhancement for active agents when compared to HP $\beta C D$ by a linear manner. The possible reason is the bigger cavity size of $\mathrm{HP} \gamma \mathrm{CD}$ which could not stabilize the host-guest interaction with cineole or $p$-cymene. On the contrary, the narrower cavity of HP $\beta C D$ provides a stable complexation with cineole or $p$-cymene in the dynamic water environment. Thus, higher amount of active agents was encapsulated within the HP $\beta C D$ cavity which leads to superior water solubility for both cineole and $p$-cymene. Actually, the highest CD concentration $(30 \mathrm{~mm})$ used revealed approximate limits for the solvation behaviour of these active agents due to the $A_{P}$-type and $A_{N^{-t y p e ~}}$ profile of phase solubility diagrams. Using phase solubility diagrams, the stability constant $\left(\mathrm{K}_{\mathrm{s}}\right)$ for these CD-IC systems was calculated according to Eqn. $1 . \mathrm{K}_{\mathrm{s}}$ values were calculated as $603,67,3928$ and $220 \mathrm{M}^{-1}$ for cineole/HP $\beta C D-I C$ and cineole/HP $\gamma \mathrm{CD}$ $\mathrm{IC}, p$-cymene/HP $\beta \mathrm{CD}$-IC and $p$-cymene/HP $\gamma \mathrm{CD}$-IC, respectively. Principally, Ks value represents the binding strength between guest molecules and $\mathrm{CD}$ cavity (Marques, 2010; Ciobanu et al., 2013). Hence, our findings suggest two things: first, $\mathrm{HP} \beta C D$ forms more stable complexes with active agents compared to $\mathrm{HP} \gamma \mathrm{CD}$, and second, $p$-cymene molecules more favourably interact with $\mathrm{CD}$ compared to cineole. The first outcome was also consistent with the TGA and ${ }^{1} \mathrm{H}-\mathrm{NMR}$ results, especially for $p$-cymene case. Regarding second finding, we observed the opposite result from TGA and ${ }^{1} \mathrm{H}-\mathrm{NMR}$ studies. However, if we consider the hydrophobicity of these two active agents, this result may be expected. As known, hydrophobicity of organic molecules determines their binding affinity with $\mathrm{CD}$ molecules. The p-cymene is more hydrophobic compared to cineole which might lead to greater complexation stability inside the apolar cavity of $\mathrm{CD}$ as it is calculated from phase solubility experiments (Ciobanu et al., 2013).

In addition to phase solubility diagrams, the water solubility enhancement of the cineole and $p$-cymene in CD-IC-NF was also demonstrated visually by dissolving CD-IC-NF samples in water. Fig. S7 and Movie S1, Movie S2 show the fast dissolution of CD-IC-NF by the addition of water. These visualizations revealed that we have achieved readily water-soluble cineole and $p$-cymene which were encapsulated in CD-IC-NF.
Moreover, having high surface area to volume ratio and nanoscale porosity provides fast-dissolving property for cineole/CD-IC-NF and $p$-cymene/CD-IC-NF webs.

\section{Conclusion}

In this study, we successfully demonstrated the production of self-standing nanofibrous webs from the inclusion complexes of CDs (i.e. HP $\beta C D$ and $\mathrm{HP} \gamma \mathrm{CD}$ ) and volatile essential oil extraction products (i.e. cineole and $p$-cymene), via electrospinning technique without using carrier polymeric matrix. The bead-free nanofiber morphology was achieved for cineole/ HP $\beta C D-I C-N F$, cineole/HP $\gamma$ CD-IC-NF and $p$-cymene/HP $\beta C D$-IC-NF samples whereas $p$-cymene/ $\mathrm{HP} \gamma \mathrm{CD}-\mathrm{IC}-\mathrm{NF}$ has beaded nanofiber morphology. The FTIR and ${ }^{1} \mathrm{H}-\mathrm{NMR}$ studies prove the existence of cineole and $p$-cymene in the CD-IC-NF. Additionally, the amount of cineole and $p$-cymene in CD-IC-NF was calculated from the ${ }^{1} \mathrm{H}-\mathrm{NMR}$ measurements, and it was found out that the significant amount of cineole and $p$-cymene was preserved in the CD-IC-NF owing to complexation with $\mathrm{CD}$. ${ }^{1} \mathrm{H}-\mathrm{NMR}$ results revealed that cineole/HP $\beta C D-I C-N F$, cineole $/ \mathrm{HP} \gamma \mathrm{CD}-\mathrm{IC}-\mathrm{NF}$, $p$-cymene/HP $\beta \mathrm{CD}$-IC-NF and $p$-cymene/HP $\gamma \mathrm{CD}$-ICNF preserved up $68.4 \%, 78.1 \%, 54.5 \%$ and $44.0 \%$ of initial amount of active agents, respectively. TGA measurements indicated the complex formation between cineole or $p$-cymene and CD for CD-IC-NF samples as thermal evaporation of cineole (up to $270{ }^{\circ} \mathrm{C}$ ) and $p$-cymene (up to $275^{\circ} \mathrm{C}$ ) was shifted to much higher temperature when compared to their pure form (below $100{ }^{\circ} \mathrm{C}$ ). That is, CD-IC-NF samples have shown enhanced thermal stability for cineole and $p$-cymene due to the inclusion complex formation. The water solubility of both cineole and $p$-cymene was improved with $\mathrm{CD}$ as proven by phase solubility diagrams of CD-IC systems. Finally, it was observed that the CD-IC-NF self-standing nanofibrous webs were quickly dissolved in water. To conclude, both the thermal stability and the water solubility of cineole and $p$-cymene are improved by the inclusion complexation with $\mathrm{CD}$. Moreover, these CD-IC systems were transformed into self-standing and easily handled nanofibrous web forms compared to their powder form along with the efficient preservation of cineole and $p$-cymene. In brief, depending on the specific properties of cineole and $p$-cymene; cineole/CD-IC-NF and $p$-cymene/CD-IC-NF would be rather attractive in food and oral care applications as fast-dissolving supplement material or oral care strip due to their self-standing and high surface area nanofibrous web form and, high thermal stability and enhanced water solubility of cineole and p-cymene. 


\section{Acknowledgment}

The Scientific and Technological Research Council of Turkey (TUBITAK, project \# 213M185) is acknowledged for funding the research. T. U. also thanks Turkish Academy of Sciences- Outstanding Young Scientists Award Program (TUBA-GEBIP) for partial funding. A. C. and Z. I. Y thank TUBITAK-BIDEB for the $\mathrm{PhD}$ scholarship.

\section{References}

Astray, G., Mejuto, J., Morales, J., Rial-Otero, R. \& SimalGándara, J. (2010). Factors controlling flavors binding constants to cyclodextrins and their applications in foods. Food Research International, 43, 1212-1218.

Aytac, Z., Dogan, S.Y., Tekinay, T. \& Uyar, T. (2014). Release and antibacterial activity of allyl isothiocyanate/ $\beta$-cyclodextrin complex encapsulated in electrospun nanofibers. Colloids and Surfaces B: Biointerfaces, 120, 125-131.

Aytac, Z., Yildiz, Z.I., Kayaci-Senirmak, F., Keskin, N.O., Tekinay, T. \& Uyar, T. (2016a). Electrospinning of polymer-free cyclodextrin/geraniol-inclusion complex nanofibers: enhanced shelf-life of geraniol with antibacterial and antioxidant properties. RSC Advances, 6, 46089-46099.

Aytac, Z., Yildiz, Z.I., Kayaci-Senirmak, F. et al. (2016b). Fast-Dissolving, Prolonged Release, and Antibacterial Cyclodextrin/Limonene-Inclusion Complex Nanofibrous Webs via Polymer-Free Electrospinning. Journal of Agricultural and Food Chemistry, 64, 7325-7334.

Aytac, Z., Yildiz, Z.I., Kayaci-Senirmak, F., Tekinay, T. \& Uyar, T. (2017). Electrospinning of cyclodextrin/linalool-inclusion complex nanofibers: fast-dissolving nanofibrous web with prolonged release and antibacterial activity. Food Chemistry, 231, 192-201.

Bakkali, F., Averbeck, S., Averbeck, D. \& Idaomar, M. (2008). Biological effects of essential oils-a review. Food Chemistry and Toxicology, 46, 446-475.

Celebioglu, A. \& Uyar, T. (2011). Electrospinning of Polymer-free Nanofibers from Cyclodextrin Inclusion Complexes. Langmuir, 27, 6218-6226.

Celebioglu, A. \& Uyar, T. (2012). Electrospinning of nanofibers from non-polymeric systems: polymer-free nanofibers from cyclodextrin derivatives. Nanoscale, 4, 621-631.

Celebioglu, A. \& Uyar, T. (2017). Antioxidant Vitamin E/Cyclodextrin Inclusion Complex Electrospun Nanofibers: enhanced watersolubility, prolonged shelf-life and photostability of Vitamin E. Journal of Agricultural and Food Chemistry, 56, 5404-5412.

Celebioglu, A., Umu, O.C., Tekinay, T. \& Uyar, T. (2014). Antibacterial electrospun nanofibers from triclosan/cyclodextrin inclusion complexes. Colloids and Surfaces B: Biointerfaces, 116, 612-619.

Celebioglu, A., Kayaci-Senirmak, F., Ipek, S., Durgun, E. \& Uyar, T. (2016). Polymer-free nanofibers from vanillin/cyclodextrin inclusion complexes: high thermal stability, enhanced solubility and antioxidant property. Food \& Function, 7, 3141-3153.

Ciobanu, A., Mallard, I., Landy, D., Brabie, G., Nistor, D. \& Fourmentin, S. (2013). Retention of aroma compounds from Mentha piperita essential oil by cyclodextrins and crosslinked cyclodextrin polymers. Food Chemistry, 138, 291-297.

Higuchi, T. \& Connors, A.K. (1965). Phase-solubility techniques. Advances in Chemical Instrumentation, 4, 117-212.

Hu, X., Liu, S., Zhou, G., Huang, Y., Xie, Z. \& Jing, X. (2014). Electrospinning of polymeric nanofibers for drug delivery applications. Journal of Controlled Release, 185, 12-21.
Kayaci, F. \& Uyar, T. (2012). Encapsulation of vanillin/cyclodextrin inclusion complex in electrospun polyvinyl alcohol (PVA) nanowebs: prolonged shelf-life and high temperature stability of vanillin. Food Chemistry, 133, 641-649.

Kayaci, F., Ertas, Y. \& Uyar, T. (2013). Enhanced Thermal Stability of Eugenol by Cyclodextrin Inclusion Complex Encapsulated in Electrospun Polymeric Nanofibers. Journal of Agricultural and Food Chemistry, 61, 8156-8165.

Kayaci, F., Sen, H.S., Durgun, E. \& Uyar, T. (2014). Functional electrospun polymeric nanofibers incorporating geraniol-cyclodextrin inclusion complexes: high thermal stability and enhanced durability of geraniol. Food Research International, 62, 424-431.

Marques, H.M. (2010). A review on cyclodextrin encapsulation of essential oils and volatiles. Flavour and Fragrance Journal, 25, 313-326.

Mittal, V., Pérez-Mariá, R., Fabra, M.J., Lagarón, J.M. \& LópezRubio, A. (2012). Use of Electrospinning for Encapsulation. Beverly: Scrivener Publishing LLC.

Narishetty, S.T. \& Panchagnula, R. (2005). Effect of 1-menthol and 1,8-cineole on phase behavior and molecular organization of SC lipids and skin permeation of zidovudine. Journal of Controlled Release, 102, 59-70.

Navarro, P., Melendez-Martinez, A.J., Heredia, F. et al. (2011). Effects of $\beta$-cyclodextrin addition and farming type on vitamin $\mathrm{C}$, antioxidant activity, carotenoids profile, and sensory analysis in pasteurised orange juices. International Journal of Food Science \& Technology, 46, 2182-2190.

Noruzi, M. (2016). Electrospun nanofibres in agriculture and the food industry: a review. Journal of the Science of Food and Agriculture, 96, 4663-4678.

Serafini, M.R., Menezes, P.P., Costa, L.P. et al. (2011). Interaction of p-cymene with $\beta$-cyclodextrin. Journal of Thermal Analysis and Calorimetry, 109, 951-955.

Szejtli, J. (1998). Introduction and General Overview of Cyclodextrin Chemistry. Chemical Reviews, 98, 1743-1754.

Uyar, T. \& Besenbacher, F. (2008). Electrospinning of uniform polystyrene fibers: the effect of solvent conductivity. Polymer, 49, 5336-5343.

Uyar, T., Nur, Y., Hacaloglu, J. \& Besenbacher, F. (2009a). Electrospinning of functional poly(methyl methacrylate) nanofibers containing cyclodextrin-menthol inclusion complexes. Nanotechnology, 20, 125703.

Uyar, T., Hacaloglu, J. \& Besenbacher, F. (2009b). Electrospun polystyrene fibers containing high temperature stable volatile fragrance/flavor facilitated by cyclodextrin inclusion complexes. Reactive and Functional Polymers, 69, 145-150.

Uyar, T., Hacaloglu, J. \& Besenbacher, F. (2011). Electrospun Polyethylene Oxide (PEO) Nanofibers Containing Cyclodextrin Inclusion Complex. Journal of Nanoscience and Nanotechnology, 11, 3949-3958.

Valle, E.D. (2004). Cyclodextrins and their uses: a review. Process Biochemistry, 39, 1033-1046.

Wendorff, J.H., Agarwal, S. \& Greiner, A. (2012). Electrospinning: Materials, Processing and Applications. Weinheim: John Wiley \& Sons. Yalkowsky, S. \& He, Y. (2003). Handbook of Aqueous Solubility Data. Boca Raton: CRC Press, Taylor \& Francis Group.

\section{Supporting Information}

Additional Supporting Information may be found in the online version of this article:

Figure S1. (a) Schematic representation of the electrospinning of CD-IC-NF. Representative photographs of electrospun webs of (b) cineole/HP $\beta C D-I C-N F$, (c) cineole/HP $\gamma$ CD-IC-NF, (d) $p$-cymene/HP $\beta C D-I C-N F$ and (e) $p$-cymene/HP $\gamma$ CD-IC-NF. 
Figure S2. Fiber diameter distributions with average fiber diameter (AFD) of the electrospun nanofibers; (a) cineole $/ \mathrm{HP} \beta \mathrm{CD}-\mathrm{IC}-\mathrm{NF}$, (b) cineole $/ \mathrm{HP} \gamma \mathrm{CD}-\mathrm{IC}-\mathrm{NF}$ and (c) $p$-cymene/HP $\beta \mathrm{CD}$-IC-NF.

Figure S3. FTIR spectra of (a) cienole, cineole/ HP $\beta C D-I C-N F$, cineole/HP $\gamma$ CD-IC-NF and (b) $p$ cymene, $p$-cymene/HP $\beta C D$-IC-NF, $p$-cymene/HP $\gamma \mathrm{CD}$ IC-NF.

Figure S4. ${ }^{1} \mathrm{H}-\mathrm{NMR}$ spectra of (a) cineole/HP $\beta \mathrm{CD}$ IC-NF, (b) cineole/HP $\gamma \mathrm{CD}-\mathrm{IC}-\mathrm{NF}$, (c) p-cymene/ HP $\beta C D$-IC-NF and (d) $p$-cymene/HP $\gamma$ CD-IC-NF dissolved in $d 6$-DMSO.

Figure S5. The derivative TGA thermogram of (a) cienole, cineole/HP $\beta \mathrm{CD}-\mathrm{IC}-\mathrm{NF}$, cineole/HP $\gamma \mathrm{CD}-\mathrm{IC}-$ $\mathrm{NF}$ and (b) $p$-cymene, $p$-cymene/HP $\beta C D$-IC-NF, $p$ cymene $/ \mathrm{HP} \gamma \mathrm{CD}-\mathrm{IC}-\mathrm{NF}$.

Figure S6. Phase solubility diagram of (a) cineole/ HP $\beta C D-I C, \quad$ (b) cineole/HP $\gamma$ CD-IC, (c) p-cymene/
HP $\beta C D$-IC and (d) p-cymene/HP $\gamma$ CD-IC systems $(n=3)$.

Figure S7. Presentation of the solubility behaviour of (a) cineole/HP $\beta C D-I C-N F$, (b) cineole/HP $\gamma$ CD-IC$\mathrm{NF}$, (c) $p$-cymene/HPßCD-IC-NF and (d) $p$-cymene/ $\mathrm{HP} \gamma \mathrm{CD}-\mathrm{IC}-\mathrm{NF}$. The pictures are taken after a very few seconds of water exposure.

Table S1. Properties of the electrospinning solutions and the electrospun nanofibers.

Table S2. ${ }^{1} \mathrm{H}-\mathrm{NMR}$ and TGA calculations for the active agent amount in CD-IC-NF in terms of molar ratio (CD:active agents) $/ \%(\mathrm{w} / \mathrm{w})$ comparatively with their initial values.

Movie S1. Video showing the water solubility of cineole/CD-IC-NF.

Movie S2. Video showing the water solubility of $p$-cymene/CD-IC-NF. 